\title{
Experimental investigation of shell-and-tube heat exchanger with different type of baffles
}

\author{
Pooja J. Pawar ${ }^{*}$ and Rupesh J. Yadav ${ }^{\dagger}$ \\ ${ }^{\dagger}$ Department of Mechanical Engineering MIT College of Engineering Pune 411038, India.
}

Accepted 15 June 2016, Available online 20 June 2016, Special Issue-5 (June 2016)

\begin{abstract}
In last two decades many technical, experimental and numerical models are being presented on shell and tube heat exchanger by many researchers. In industries shell and tube heat exchangers are used for different applications e.g. for waste heat recovery, oil refineries etc. This paper focus on the experimental investigation of shell and tube heat exchanger with different type of baffles. The shell and tube heat exchanger with segmental baffles and flower baffles are designed, fabricated and tested. The thermal and hydraulic performance of both heat exchangers are compared with same operating conditions. The heat exchanger with flower baffle gives more efficient overall performance up to 25-32\% than segmental baffles heat exchanger. Also the pressure drop gets reduced in flower baffle heat exchanger up to $20-28 \%$ than segmental baffles heat exchanger.
\end{abstract}

Keywords: shell and tube heat exchanger, Segmental baffles, flower baffles, overall performance, Pressure drop.

\section{Introduction}

Shell-and-tube heat exchangers (STHXs) are widely applied in various industrial fields such as power generation and chemical process, petroleum refining, waste heat recovery, condensers, steam generation set. Shell-and -tube heat exchanger gives relatively high ratio of heat transfer area to volume. It can be easily cleaned. It is more flexible than other type of heat exchanger. It can be design for high pressure environment and fluid steams having high pressure difference.

Various geometrical modification has been done in shell and tube heat exchanger to increase thermal and hydraulic performance. The heat exchanger with segmental baffle(SB-STHX) gives low thermal performance i.e. it gives low heat transfer coefficient and the leakages are more so the pressure drop is also more and because of this the overall performance gets reduced. To overcome with this problem flower baffles are used (Youghu You 2012). Geometry of flower baffles is simple and are easy to manufacture compare to segmental baffles.

\section{Configuration and fabrication of STHXs with different type of baffles.}

The STHXs with helical and V-type of baffles gives better overall performance but they are difficult to manufacture. Segmental baffles are easy to manufacture but the pressure drop is higher. Fig 1. shows segmental baffle arrangement in STHX. Fig 2. shows flower baffle arrangement in STHX.

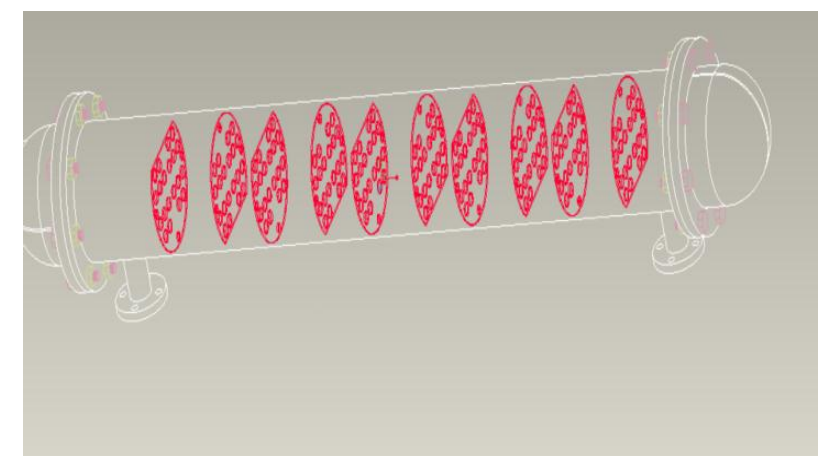

Fig.1 Segmental baffle arrangement in STHX

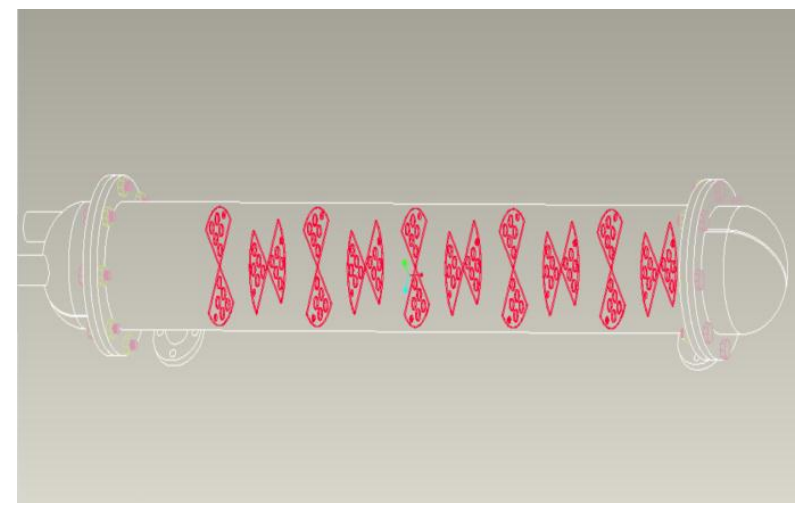

Fig .2 Flower baffle arrangement in STHX 
Fabrication of segmental and flower baffle is same.

Table1. Structure parameter of SG-STHX

\begin{tabular}{|c|c|}
\hline Shell inner dia: $\phi 132 \mathrm{~mm}$ & $\begin{array}{c}\text { Tube effective length: } \\
1000 \mathrm{~mm}\end{array}$ \\
\hline Shell side fluid : cool water & $\begin{array}{c}\text { Tube side fluid: warm } \\
\text { water }\end{array}$ \\
\hline Number of tube: 20 & $\begin{array}{c}\text { Tube arrangement : } \\
\text { triangular }\end{array}$ \\
\hline Number of tube passes: 4 & Number of baffles:10 \\
\hline Tube pitch:1.625mm & Baffle spacing:85mm \\
\hline Tube 0D:13mm & Pull rod diameter:8mm \\
\hline Tube ID:9mm & $\begin{array}{c}\text { Heat transfer area } \\
: 0.8168 \mathrm{~m}^{2}\end{array}$ \\
\hline Number of pull rod:4 & $\begin{array}{c}\text { Tube side flow area: } \\
0.000318 \mathrm{~m}^{2}\end{array}$ \\
\hline
\end{tabular}

Table2. Structure parameter of FB-STHX

\begin{tabular}{|c|c|}
\hline Shell inner dia: $\phi 132 \mathrm{~mm}$ & $\begin{array}{c}\text { Tube effective length: } \\
1000 \mathrm{~mm}\end{array}$ \\
\hline Shell side fluid : cool water & $\begin{array}{c}\text { Tube side fluid: warm } \\
\text { water }\end{array}$ \\
\hline Number of tube:20 & $\begin{array}{c}\text { Tube arrangement : } \\
\text { triangular }\end{array}$ \\
\hline Number of tube passes:4 & Number of baffles: 10 \\
\hline Tube pitch:1.625mm & Baffle spacing: $85 \mathrm{~mm}$ \\
\hline Tube OD:13mm & Pull rod diameter:8mm \\
\hline Tube ID:9mm & Baffle Angle geometry - $90^{0}$ \\
\hline Number of pull rod:4 & $\begin{array}{c}\text { Baffle arrangement: } \\
\text { staggered }\end{array}$ \\
\hline
\end{tabular}

Table number 1 and 2 shows that structural parameter of SG-STHX and FB-STHX respectively

\section{Experimental set up and procedure}

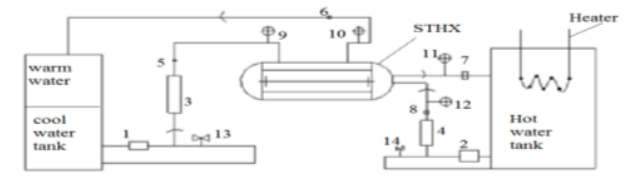

Fig. 3 Schematic diagram of experimental setup 1,2 Motors 3,4 Rotameters 5,6,7,8 Thermocouples 9,10,11,12 Pressure transducer 13,14 valves

Fig 3 shows schematic diagram of experimental setup for both the heat exchanger.

Hot water loop: cool water gets heated with help of electrical heater. The hot water flows from a water tank via tube into a tube side of STHX. Tube side Outlet also connected to the hot water tank so that fluid can have used for recirculate.

Cool water Tank: Tank contains a tab water which is used as cool water. It supplies as inlet fluid of shell in STHX. Outlet of shell connected with warm water tank to collect and recirculate the warm water.
Rotameters: It is used to measure and control flow of both side fluids.

Thermocouples: K-type of thermocouples are used to measure temperature of both side fluids $5,6,7,8$ as shown in fig 3.

Pressure transducer: Used to measure inlet and outlet pressure of tube and shell side of STHX. Valves: used to control flow of fluids.

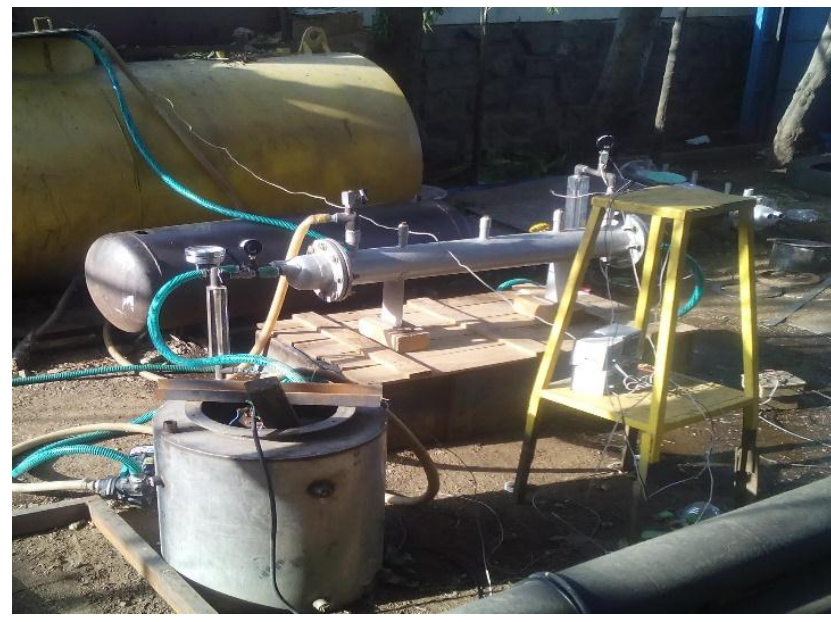

Fig 4. Photo of Experimental set up of STHX

Fig 4 shows the photos of both STHXs and experimental setup.

\section{Data reduction}

In experiments flow rates, pressure drop, temperatures of shell side and tube side fluids of STHXs were measured. Energy balance calculated with help of flow rates, temperatures of both side of fluid. The heat balance was considered to be achieved when the energy imbalance is less than $5 \%$. Based on the energy balance between the shell side and tube side, the overall heat transfer coefficient of the STHX can be calculated. The same procedure is applied for both the heat exchanger. Tube side heat transfer coefficient is calculated by using Gnielinski's correlation. Shell side heat transfer coefficient is calculated with the help of overall heat transfer coefficient and tube side heat transfer coefficient as shown in eq. 1 .

Over all heat transfer coefficient calculated by using formula

$\frac{1}{U o}=\frac{1}{h o}+R w+R f i+R f o+\frac{d o}{d i * h i}$

Where Uo is over all heat transfer coefficient, hi is tube side heat transfer coefficient, ho is shell side heat transfer coefficient, Rfi, fouling coefficient for tube side, Rfo, fouling coefficient for shell side, Rw, thermal resistance for tube wall.

Since the heat exchangers used for experiment are newly fabricated, the effects of the two fouling resistance are negligible. Therefore, the above equation can be expressed as 
$\frac{1}{U o}=\frac{1}{h o}+R w+\frac{d o}{d i * h i}$

Overall heat transfer coefficient achieved based on heat transfer correlation

$U o=\frac{Q a v g}{A h * \Delta T \operatorname{Tlm}(a c t)}$

Where $\mathrm{Ah}$ is heat transfer area in $\mathrm{m}^{2}, \Delta \mathrm{Tlm}$ is logarithmic temperature difference(LMTD). Qavg is average heat flux of cold and warm fluid.

$A h=\pi *$ do $*$ Leff $* \mathrm{~N}$

Leff is effective length of tube used for heat transfer, do is outer diameter of tube, and $\mathrm{N}$ is number of tubes.

For four pass tube heat exchanger we have to used LMTD correction factor for that we have calculate $R$ and $\mathrm{P}$ ratio. With help $\mathrm{R}, \mathrm{P}$ ratio and TEMA chart we will get correction factor $\mathrm{F}$.

$R=\frac{T h 1-T h 2}{T c 2-T c 1}$

And

$P=\frac{T c 2-T c 1}{T h 1-T c 1}$

So $\Delta \mathrm{T}_{\operatorname{lm}}($ actual $)=\mathrm{F}^{*} \Delta \mathrm{T}_{\mathrm{lm}}$

Since Th1 is shell side fluid inlet temp, Th2 is shell side fluid outlet temp, Tc1 is tube side fluid inlet temp, Tc2 is tube side fluid outlet temp.

Shell side and tube side heat transfer achieved by using following correlation.

$Q=m^{*} * C p * \Delta T$

$\mathrm{m}$ is fluid mass flowrate, $\mathrm{kg} / \mathrm{s}$; $\mathrm{Cp}$, specific heat under constant pressure, $\Delta \mathrm{T}$ is temperature difference. So overall heat transfer coefficient obtained by using eq 3 and 7. Thermal resistance can be calculated by

$R w=\frac{d o * \ln \left(\frac{d o}{d i}\right)}{2 * k m}$

Since do and di is outer and inner diameter of tube and $\mathrm{Km}$ is thermal conductivity of tube material.

Tube side heat transfer correlation is calculated by using Gnielinski's correlation

$N u=\frac{\left(\frac{f}{2}\right) *(R e-1000) * \operatorname{Pr}}{1+12.7 *\left(\frac{\mathrm{f}}{2}\right)^{\frac{1}{2}} *\left(\operatorname{Pr}^{\frac{2}{3}}-1\right)}$

$\mathrm{Nu}$ is Nusselt number, $\mathrm{Pr}$ is Prandtl Number, Re Reynolds Number and $\mathrm{f}$ is friction factor.

$N u=\frac{h i * k}{d i}$

Friction factor calculated by $f=(1.35 * \ln (R e)-3.28)^{-2}$

Reynolds number is achieved from the following equation.

$R e=(\rho * u * d i) / \mu$

So from equation number 11 we can calculate tube side heat transfer coefficient and from equation number 2 we get shell side heat transfer coefficient.

\section{Experimental Results and Analysis}

The experiments were conducted for the two types of STHXs described in Sect.3, in which hot water flow through the tube side and cold water flow through the shell side of the STHXs. Performance of two STHXs are compared.

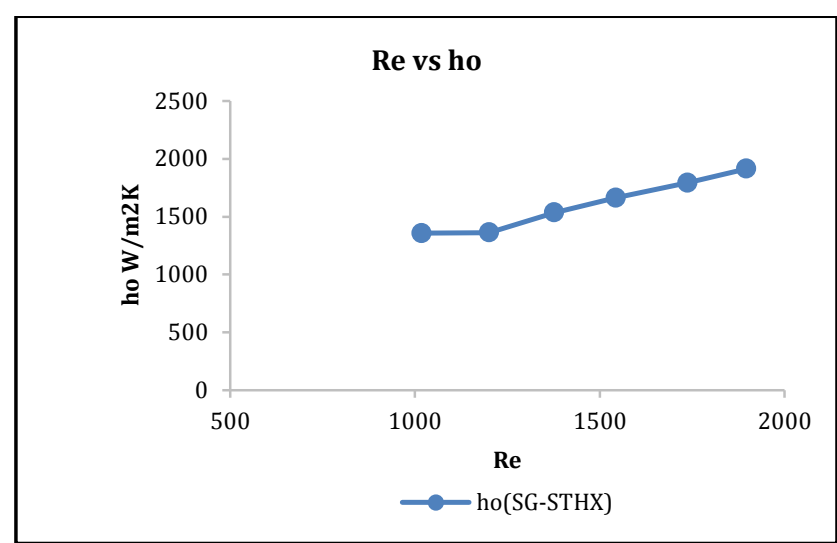

Fig 5. Variation of ho (shell side heat transfer coefficient) with Reynolds number

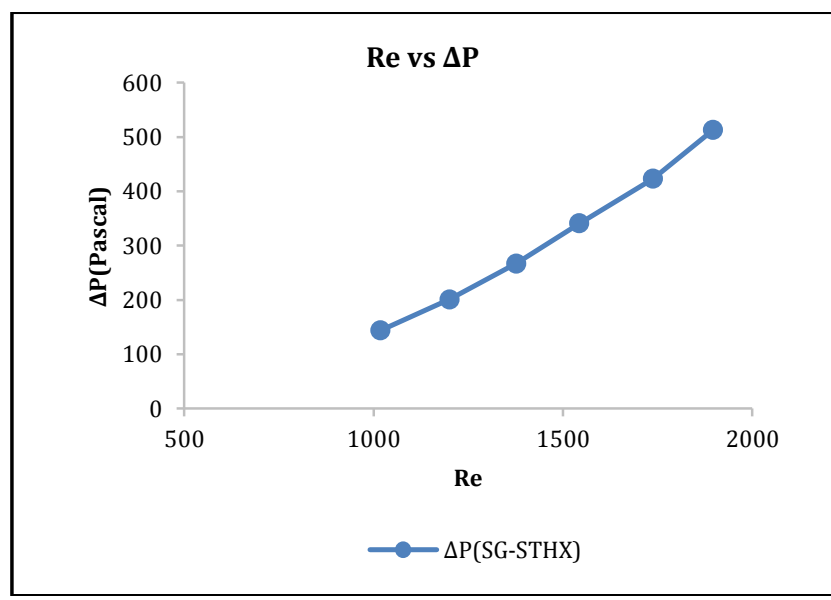

Fig 6. Variation of pressure drop with Reynolds number

Fig 5 shows the graph between Reynolds number of shell side fluid and shell side heat transfer of SG-STHX. It shows that as Re increases heat transfer coefficient also increases. Fig 6 shows the graph between Reynolds number of shell side fluid and shell side pressure drop of SG-STHX. It shows that when Re 
increases pressure drop also increases. A good agreement between the available literature is found with the experimental results.

\subsection{Comparison between two STHXS}

The comparison of two STHXS are carried out for checking the performance improvement with modification of baffles.

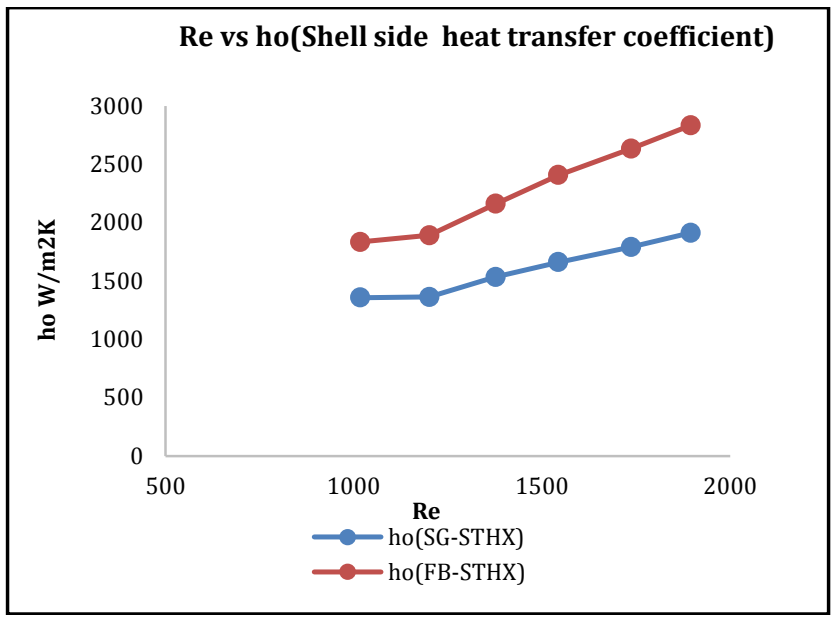

Fig 7. Comparison of ho with Reynolds number between two STHXs at tube side velocity is $0.89 \mathrm{~m} / \mathrm{s}$

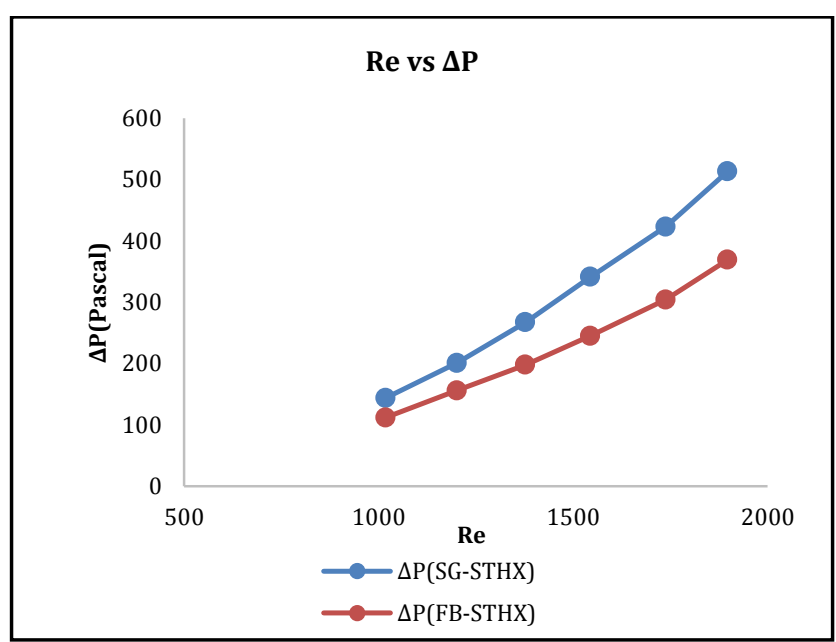

Fig 8. Comparison of pressure drop with Reynolds number between two STHXs at tube side velocity is $0.89 \mathrm{~m} / \mathrm{s}$

Fig no 7 shows the shell side heat transfer coefficient comparison between SG-SHTX and FB-STHX. From fig 7 we can conclude that shell side heat transfer coefficient in FB-STHX is more than SG-STHX. It increases up to 35-46\%. So FB-STHX is more efficient than SG-STHX.

Fig no 8 shows the pressure drop comparison between SG-SHTX and FB-STHX. From fig 8 we can conclude that pressure drop in FB-STHX is less than SG-STHX. It decreases up to $25-30 \%$. So FBDT-STHX is more efficient than SG-STHX.

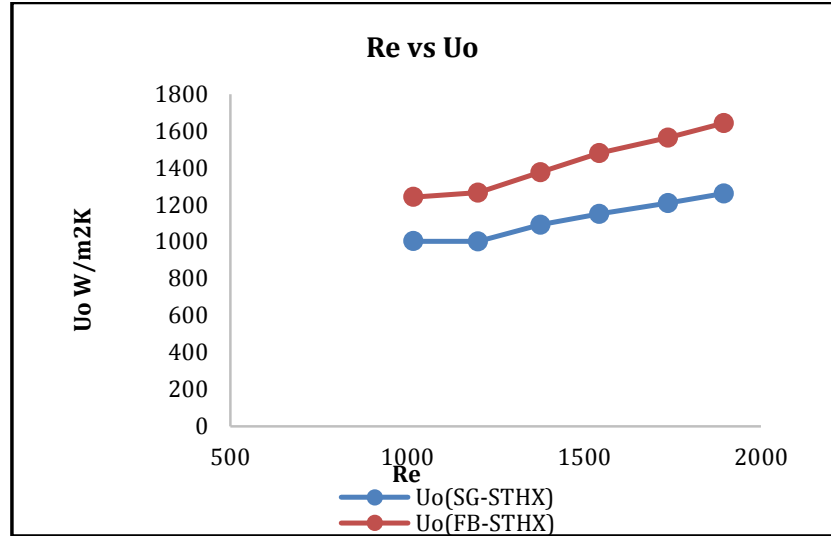

Fig 9. Comparison of Uo with Reynolds number between two STHXs at tube side velocity is $0.89 \mathrm{~m} / \mathrm{s}$

Fig 9 shows the overall heat transfer coefficient comparison between two STHXs at tube side velocity is $0.89 \mathrm{~m} / \mathrm{s}$. Graph is plotted Re Vs overall heat transfer coefficient. From graph we can conclude that overall heat transfer coefficient in FB-STHX is more compare to SG-STHX. It increases up 25-32\%.

\section{Conclusion}

In a shell and tube heat exchanger compare to segmental and helical baffle, flower baffle gives better thermal and hydraulic performance. Also manufacturing of flower baffles is easy compare to helical baffle. Experimental results show that

1) Shell side heat transfer coefficient in FB-STHX increases up to $35-46 \%$ than SG-STHX at same shell side Reynolds number and at tube side velocity of $0.89 \mathrm{~m} / \mathrm{s}$.

2) Pressure drop in FB-STHX is less than SG-STHX Pressure drop decreases up to $20-28 \%$. Under same operating condition i.e. at same shell side Reynolds number and at tube side velocity of 0.89 $\mathrm{m} / \mathrm{s}$.

3) Overall heat transfer coefficient in FB-STHX increases up to $25-32 \%$ than SG-STHX at same operating conditions i.e. same shell side Reynolds number and at tube side velocity of $0.89 \mathrm{~m} / \mathrm{s}$.

\section{Nomenclature}

$\begin{array}{ll}\text { A } & \text { area }\left(\mathrm{m}^{2}\right) \\ \mathrm{Cp} & \text { specific heat }(\mathrm{J} / \mathrm{kgK}) \\ \mathrm{do} & \text { outer diameter of tube }(\mathrm{m}) \\ \mathrm{di} & \text { inner diameter of tube }(\mathrm{m}) \\ \mathrm{f} & \text { friction factor } \\ \text { ho } & \text { shell side heat transfer coefficient }\left(\mathrm{W} / \mathrm{m}^{2} \mathrm{~K}\right) \\ \mathrm{hi} & \text { tube side heat transfer coefficient }\left(\mathrm{W} / \mathrm{m}^{2} \mathrm{~K}\right) \\ \mathrm{k} & \text { thermal conductivity }(\mathrm{W} / \mathrm{Mk}) \\ \mathrm{Leff} & \text { effective length }(\mathrm{m}) \\ \mathrm{m} & \text { mass flow rate }(\mathrm{kg} / \mathrm{sec}) \\ \mathrm{N} & \text { number of tubes } \\ \mathrm{Nu} & \text { Nussult number }\end{array}$


$\mathrm{P} \quad$ pressure $(\mathrm{Pa})$

Pr Prandtl Number

Q Heat Exchange quality(W)

Re Reynolds number

Rfi fouling coefficient for tube side $\left(\mathrm{m}^{2} \mathrm{~K} / \mathrm{W}\right)$

Rfo fouling coefficient for shell side $\left(\mathrm{m}^{2} \mathrm{~K} / \mathrm{W}\right)$

$\mathrm{R}_{\mathrm{w}} \quad$ thermal resistance for tube wall $\left(\mathrm{m}^{2} \mathrm{~K} / \mathrm{W}\right)$

$\mathrm{T}$ temperature $\left({ }^{\circ} \mathrm{C}\right)$

$\mathrm{u} \quad$ velocity $(\mathrm{m} / \mathrm{s})$

Uo overall heat transfer coefficient $\left(\mathrm{W} / \mathrm{m}^{2} \mathrm{~K}\right)$

\section{Greek symbols}

$\rho \quad$ density $\left(\mathrm{kg} / \mathrm{m}^{3}\right)$

$\mu \quad$ dynamic viscosity $\left(\mathrm{Ns} / \mathrm{m}^{2}\right)$

\section{Acknowledgement}

The author would like to thank SAZ Boilers Pune for their financial support.

\section{References}

Yingshuang Wang,Zhichun Liu,Suyi Huang,Wei Liu,Weiwei Li (2011) Experimental investigation of shell-and-tube heat exchanger with new type of baffles, Heat and Mass Transfer 47,833-839.

Yonghua You, Aiwu Fan, Suyi Huang, Wei Liu, (2012) Numerical modeling and experimental validation of heat transfer and flow resistance on the shell side of a shell-and-tube heat exchanger with flower baffles, International Journal of Heat and Mass Transfer 55, 7561-7569.

Juin Chen, Hans Muller-Steinhagen, Geoffrey G. Duffy, (2001) Heat transfer enhancement in dimpled tubes, Applied Thermal Engineering 21, 535 \pm 547 .

M. Siddique, A.-R. A. Khaled, N. I. Abdulhafiz, and A. Y. Boukhary(2010)Recent Advances in Heat Transfer Enhancements: Areview report, International Journal of Chemical Engineering2010, 28

Liu, S, and Sakr, M.A., (2013) Comprehensive review on passive heat transfer enhancements in pipe exchangers. Renewable and Sustainable Energy Reviews, .19, 64-81,

Simin Wang, Jian Wen, Yanzhong Li, (2009). An experimental investigation of heat transfer enhancement for shell and tube heat exchanger, Applied Thermal Engineering 29, 2433-2438. 